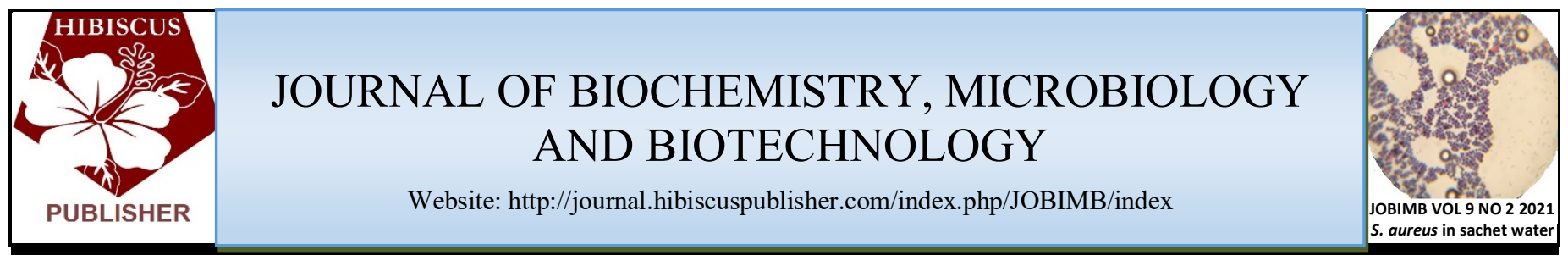

\title{
Hypoglycemic Effect of Lycopersicon esculentum (Tomato) on Alloxan- Induced Diabetic Rats
}

\author{
Abubakar Aisami ${ }^{1 *}$, Jalil Idi James ${ }^{1}$, Fatima Umar Maigari ${ }^{1}$, M. K. Atiku ${ }^{2}$ \\ ${ }^{1}$ Biochemistry Department, Gombe State University, P.M.B 127, Tudun Wada, Gombe, Nigeria. \\ ${ }^{2}$ Bayero University Kano, PMB 3011, Gwarzo Road Kano, Nigeria. \\ *Corresponding author: \\ Dr. Abubakar Aisami, \\ Biochemistry Department, \\ Gombe State University, \\ P.M.B 127, \\ Tudun Wada, \\ Gombe, \\ Nigeria. \\ Email: abubakar.aisami05@gmail.com
}

\section{HISTORY \\ Received: \\ Received in revised form \\ Accepted:}

\section{KEYWORDS}

Hypoglycemic

Lycopersicon esculentum

Tomato

Alloxan-Induced Diabetic Rats

LDL- and HDL cholesterol

\begin{abstract}
Diabetes mellitus has been a key degenerative disease affecting the world's population. Lycopersicon esculentum (Tomato), a fruit consumed by many and known to have certain phytochemicals was used to determine its hypoglycemic effect on alloxan induced diabetic rats. The tomato was dried, pulverized and dissolved in distilled water and administered orally to albino rats in various concentrations according to their body weight. 30 albino rats were divided into 6 groups of 5 rats each. Groups I and II served as normal and diabetic control respectively, while groups III to VI were induced with diabetes and treated with different concentrations of the prepared tomato. After 14 days of treatment with various concentrations of tomato, there was a marked decrease in blood sugar levels at all the study concentrations. The result of the lipid profile a significant increase $(\mathrm{p}<0.05)$ in total cholesterol $(150.67 \pm 7.02 \mathrm{mg} / \mathrm{dL})$, triglyceride $(159.33 \pm 5.03 \mathrm{mg} / \mathrm{dL})$, LDL-Cholesterol $(77.53 \pm 1.83 \mathrm{mg} / \mathrm{dL})$ and a decrease in HCL-Cholesterol $(51.67 \pm 1.00 \mathrm{mg} / \mathrm{dL})$ levels in untreated diabetic rats when compared to the normal control. Upon treatment with $200 \mathrm{mg} / \mathrm{kg}$ of tomato, there was a significant decrease $(\mathrm{p}<0.05)$ in the levels of Triglyceride, total cholesterol and LDL-cholesterol and an increase in the HDL-cholesterol. These results suggest that tomato may have the ability to reduce blood sugar level and the risk of cardiovascular disease.
\end{abstract}

\section{INTRODUCTION}

Diabetes mellitus is a set of metabolic disorders characterized by elevated blood sugar (glucose) levels, brought about by faulty secretion or action of insulin. It is a major degenerative disease in the world today affecting about 463 million adults (20-79 years) as at 2019 and is projected to rise to 700 million by 2045 [1]. It is characterized by hyperglycemia, lipoprotein abnormalities, increased basal metabolic rate [2], defect in antioxidative enzymes and increased pancreatic beta cells injury due to oxidative stress [3]. Dietary carbohydrate catabolism begins in the mouth and eventually moves to the small intestine where its product; mostly glucose, enters the bloodstream via intestinal cells. The glucose in the bloodstream is then transported to various cells. The entry of glucose into the cells is aided by insulin, this suggest that any abnormality related to insulin can starve the cells of glucose and increase blood glucose concentration. Secretion of insulin takes place in the pancreas; an organ with the ability to dictates glucose concentration in the blood and release insulin when the level of glucose is high [4]. One way to induce diabetes is by disrupting the wellbeing of the beta cells of the pancreas by the use of alloxan; a toxic glucose analogue, although streptozocin can also serve similar function $[5,6]$. It has been estimated that atleast 800 plant varieties posses the ability to reduce blood glucose level [7]. The exhorbitant prices, lack of availabilty and possible side effects of othodox medicine has led to rising demand for plants products with antidiabetic activity. Thus, different plants are constantly studied to ascertain their potency as blood glucose reducing agents.

Tomato (Lycopersicon esculentum) is a famous fruit eaten by alot of the worlds population. The carotenoid found in tomato that atrracts much attention is the lycopene; a compound that can withstand the harsh heating condition often employed during tomato processing [8]. More than $\beta$-carotene, lycopene shows the highest overall single oxygen-quenching carotenoid activity. Studies also showed the presence of quercetin (a flavonoid), vitamins $\mathrm{A}, \mathrm{E}$ and $\mathrm{C}$ in substantial amounts in tomato $[9,10]$. 
Regardless of the commercially available antidiabetic drugs, Despite the presence of known antidiabetic drugs in the markets, diabetes and the related complication continue to be of enormous concern medically. Management of diabetes devoid of side effect is still a problem to the medical community. Therefore, it is very important to investigate plants with potent antidiabetic effect for solution.

\section{MATERIALS AND METHODS}

\section{Reagents}

The analytical grade reagents obtained from Randox Laboratories Ltd., Antrim, United Kingdom were used for the analysis. The reagents include Glucose, Total protein, total cholesterol and Triglycerides kits. Other reagents used are Choloform (BDH), Alloxan monohydrate (sigma) and methylated spirit (BDH).

\section{Experimental animals}

Forty-five (45) albino rats of both sexes were purchased from University of Jos, Animal house. The animals were brought in two weeks prior to commencing the studies so as to get use to their new environment. They were fed with Grower marsh and water in cages at the animal house of the Department of Biological Sciences, Gombe State University

Preparation of the tomatoes powder from tomatoes fruit Ripe Lycopersicon escunlentum (tomato) Fruit (1500g) were procured from a nearby market in Gombe, Gombe, Nigeria and identified at the botany unit of Gombe state university. The powder was prepared from cleaned tomato, after been sliced and dried at $60{ }^{\circ} \mathrm{C}$ using water bath. The dried tomatoes were grounded into powdered form using pestle and mortar. The dried extract was stored at $4{ }^{\circ} \mathrm{C}$. The powdered tomatoes were then dissolved in distilled water and administrated orally as $50,100,150$ and $200 \mathrm{mg} / \mathrm{kg}$ body weight per day for 14 days.

\section{Experimental design}

In this experiment, a total of 30 rats (25 diabetic and 5 normal rats) weighing between 110 to $160 \mathrm{~g}$ were used. The rats were split into six (6) groups (5 diabetic and 1 normal rats) of 5 rats each. Group I are normal rats, Group II are diabetic rats (served as diabetic control), Groups III,IV,V and VI are diabetic rats given 50100150 and $200 \mathrm{mg} / \mathrm{kg}$ body of the extract orally for 14 days.

\section{Induction of diabetes}

Diabetes was induced by a single injection of newly made alloxan monohydrate $(200 \mathrm{mg}$ alloxan/ $\mathrm{kg} \mathrm{b}$.wt) dissolved in distilled water and administered intraperitoneally (IP) to rats that were denied food for at least $16 \mathrm{~h}$. Blood glucose levels were taken 72 $\mathrm{h}$ after alloxan administration using glucometer. According to [11], rats with values of Fasting blood glucose more than $200 \mathrm{mg} / \mathrm{dL}$ are to be used for the study.

\section{Sacrificing procedure and blood sample collection}

Blood samples were colleted on the 14th day of the onset of diabetes. After fourteen days of treatment, the rats were not given food for $16 \mathrm{~h}$ and made unconscious with $10 \%$ choloform before they were sacrificed by surgical dislocation of neck and letting free flow of blood into clean containers. The blood samples were left to clot and serum seperated was used to ascertain some biochemical indices.

\section{Glucose estimation}

Fasting blood sugar was estimated at $1^{\text {st }} 7^{\text {th }}$ and the $14^{\text {th }}$ days, the animals were not fed for $16 \mathrm{~h}$ before collecting their blood samples. Glucose oxidase method was employed to ascertain the level of glucose after fasting [12]. The test, standard and blank test tubes were labeled, and the appropriate amount of the reagents and samples were poured into the test tubes at room temperature. The content of the tubes was shaken and kept at 20$25{ }^{\circ} \mathrm{C}$ for $10 \mathrm{~min}$. Absorbance of sample and standard were measured within 60 min against reagent blank at a wavelength of $510 \mathrm{~nm}$ in a spectrophotometer. Glucose concentration was calculated using the expression below

Glucose concentration $=\frac{A_{\text {sample }}}{A_{\text {standard }}} \times$ Standard concentration

\section{Serum lipid profile estimation}

\section{Triglycerides}

The triglyceride levels were assayed using the method described by [13]. Briefly, Reagents and samples kept at room temperature were poured into test tubes labeled test, standard and blank, $10 \mu \mathrm{L}$ of serum and standard were added to the right test tubes and then $1000 \mu \mathrm{L}$ of the reagent was poured to all test tubes. The content of the tubes was left at room temperature for $20 \mathrm{~min}$. After $60 \mathrm{~min}$, the spectrophotometer reading was obtained at $500 \mathrm{~nm}$ for the test and standard. Triglyceride level was calculated using the expression below

Triglyceride concentration $=\frac{A_{\text {sample }}}{A_{\text {standard }}} \times 533 \mathrm{mg} / \mathrm{dL}$

\section{Total cholesterol}

This was estimated by the enzymatic endpoint manual method of [12] using the RANDOX ${ }^{(\mathrm{R})}$ kit for cholesterol estimation. $10 \mu \mathrm{L}$ of test and standard were poured into an already labeled test tubes followed by $1000 \mu \mathrm{L}$ of the reagent. After mixing for $10 \mathrm{~min}$ at room temperature, the absorbance at $500 \mathrm{~nm}$ was taken within $60 \mathrm{~min}$. Total cholesterol was calculated using the expression below

Concentration of cholesterol in sample $=\frac{A_{\text {sample }}}{A_{\text {standard }}} \times 200 \mathrm{mg} / \mathrm{dL}$

\section{Determination of HDL-cholesterol}

After precipatation of other fractions with magnesium chloride, the HDL- cholesterol content to the supernant fluid is estimated as explained for total cholesterol using method of [12].

\section{LDL- cholesterol estimation}

This is estimated using the equation [13].

$\mathrm{C}_{\mathrm{LDL}}=\mathrm{C}_{\mathrm{TCHOL}}-\left(\mathrm{C}_{\mathrm{HDL}}+\frac{T G}{5}\right)$

$\mathrm{C}=$ Concentration

$\mathrm{C}_{\text {тсноL }}=$ Total cholesterol

$\mathrm{TG}=$ Triglyceride

$\mathrm{C}_{\mathrm{HDL}}=$ High density lipoprotein cholesterol

\section{Determination of total proteins}

Total protein concentration was determined using Biuret methods [14]. Into test tubes arranged and labeled as test, standard and blank, $0.02 \mathrm{ml}$ of test and standard were poured into the right tube; then $1 \mathrm{ml}$ of reagent was added to all test tubes. The content of the tubes was mixed and kept for half an hour at room temperature. The absorbance of the sample was measured at a wavelength of $546 \mathrm{~nm}$ against blank within $60 \mathrm{~min}$ in a spectrophotometer. Total protein concentration was calculated using the expression below

\section{Calculation: \\ Total Protein Concentration $=\frac{A_{\text {sample }}}{A_{\text {standard }}} \times 190 \mathrm{~g} / \mathrm{l}$}




\section{Statistical analysis}

All numerical data obtained in this research were analysed using SPSS version 14.0.The data was evalauted using ANOVA and the result was presented in the form of Mean \pm standard deviation $(\mathrm{Mean} \pm \mathrm{SD})$.

\section{RESULTS AND DISCUSSION}

The results of fasting blood sugar for the $1 \mathrm{st}, 7 \mathrm{th}$, and $14^{\text {th }}$ days shown in Table 1. This result shows that there was no substantial difference $(p>0.05)$ in fasting blood glucose levels in the test groups in comparison with the diabetic control group $(202.33 \pm 7.07 .80 \mathrm{mg} / \mathrm{dL})$ on day one of the experiment. On the 7 th day, there was a marked difference $(\mathrm{p}<0.05)$ in fasting blood glucose level in the treatment groups compared to the values in normal $(68.67 \pm 3.80 \mathrm{mg} / \mathrm{dL})$ and diabetic $(200.53 \pm 5.50 \mathrm{mg} / \mathrm{dL})$ control groups. On the last day of the second week, as seen in Table 1, there was significant decrease $(\mathrm{p}<0.05)$ in fasting blood glucose levels in treatment groups III,IV V and VI compared to the diabetic control group $(198.21 \pm 6.10 \mathrm{mg} / \mathrm{dL})$. Again there was significant decline $(p<0.05)$ in fasting blood glucose level treatment groups in comparison to the normal control.

Table 1. Fasting blood sugar on the $1^{\text {st }}, 7^{\text {th }}$, and $14^{\text {th }}$ days.

\begin{tabular}{lllll}
\hline Group $(\mathrm{mg} / \mathrm{kg})$ & $\begin{array}{l}\text { Dosage } \\
(\mathrm{mg} / \mathrm{kg})\end{array}$ & 1st day & 7 th day & 14th day \\
\hline I Normal control & ---- & $67 \pm 7.63$ & $68.67 \pm 3.80$ & $68.33 \pm 3.51$ \\
II Diabetic control & ---- & $202.33 \pm 7.07^{*}$ & $200.53 \pm 5.5^{*}$ & $198.21 \pm 6.10^{*}$ \\
III & 50 & $198.00 \pm 7.64^{*}$ & $148.67 \pm 3.21^{* *}$ & $135.33 \pm 4.50^{* *}$ \\
IV & 100 & $199.76 \pm 1.52^{*}$ & $141.65 \pm 7.23^{* *}$ & $125.30 \pm 5.03^{* *}$ \\
V & 150 & $200.33 \pm 2.00^{*}$ & $141.67 \pm 1.52^{* *}$ & $118.00 \pm 8.06^{* *}$ \\
VI & 200 & $200.33 \pm 2.51^{*}$ & $136.33 \pm 4.16^{* *}$ & $108.01 \pm 0.5^{* *}$
\end{tabular}

Note: The values in the Table are mean \pm standard deviation of fasting blood sugar determination $\mathrm{n}=5$. A single asterisk shows a significant difference from the normal control $(\mathrm{p}<0.05)$ while double asterisks shows a significant difference from the diabetic control $(\mathrm{p}<0.05)$.

In Table 2 there was a signicant decrease $(p<0.05)$ in the total cholesterol in the treatment groups compared with the diabetic control.Similarly, groups III and IV showed a significant difference $(p<0.05)$ compared with the normal control. There was an increased in the HDL-cholesterol level compared with the diabetic control, all treatment groups displayed a reasonable difference $(\mathrm{p}<0.05)$ compared with the normal control. As presented in Table 2 , there was a significant decrease $(p<0.05)$ in triglyceride in the treatment groups compared with the diabetic control.The levels of serum LDL cholesterol reduced significantly $(\mathrm{p}<0.05)$ compared with the diabetic control. Table 2 also shows the levels of serum total protein. The result shows that there was no significant difference $(p>0.05)$ between the normal control and the treatment groups, but there was a significant difference $(\mathrm{p}<0.05)$ between the serum total protein levels in the diabetic control and the treatment groups.

Table 2. Effect of Lycopersicon esculentum (tomato) administration on Serum lipid profile and total serum protein in diabetic rats.

\begin{tabular}{|c|c|c|c|c|c|c|}
\hline Gp. & $\begin{array}{l}\text { Dosage } \\
(\mathrm{mg} / \mathrm{kg})\end{array}$ & $\begin{array}{l}\text { TG } \\
(\mathrm{mg} / \mathrm{dL})\end{array}$ & $\begin{array}{l}\text { TC } \\
(\mathrm{mg} / \mathrm{dL})\end{array}$ & $\begin{array}{l}\text { HDL-CH } \\
(\mathrm{mg} / \mathrm{dL})\end{array}$ & $\begin{array}{l}\text { LDL-CH } \\
(\mathrm{mg} / \mathrm{dL})\end{array}$ & $\begin{array}{l}\text { TP } \\
(\mathrm{g} / \mathrm{dl})\end{array}$ \\
\hline I & $\begin{array}{l}\text { Normal } \\
\text { control }\end{array}$ & $106.33 \pm 4.50$ & $61.23 \pm 1.10$ & $63.00 \pm 5.19$ & $30.80 \pm 2.50$ & $6.57 \pm 0.74$ \\
\hline II & $\begin{array}{l}\text { Diab } \\
\text { contr }\end{array}$ & $159.33 \pm 5.03 *$ & $150.67 \pm 7.02 *$ & $51.67 \pm 1.00^{*}$ & $77.53 \pm 1.83^{*}$ & $9.00 \pm 0.50$ \\
\hline III & 50 & & & & & \\
\hline IV & 10 & & & & & \\
\hline & & & & & & \\
\hline VI & 200 & $107.33 \pm 2.51 *$ & $67.40 \pm 2.35^{* *}$ & $58.00 \pm 5.19^{* *}$ & $* 35.85 \pm 3.33 * *$ & $6.83 \pm 0.55$ \\
\hline
\end{tabular}

Note: The values in the Table are mean \pm standard deviation of serum lipid profile and total protein determination $\mathrm{n}=5$. A single asterisk shows a significant difference from the normal control $(\mathrm{p}<0.05)$ while double asterisks shows a significant difference from the diabetic control $(\mathrm{p}<0.05) . \mathrm{TG}=$ Triglyceride; $\mathrm{TC}=$ Total cholesterol; HDL-CH $=$ High density lipoprotein cholesterol; LDL-CH= Low density lipoprotein cholesterol

$\mathrm{TP}=$ Total protein

\section{DISCUSSION}

This study checked the action of tomato in reducing the level of high blood sugar caused by alloxan in albino rats. The normal control group had normal fasting blood glucose level while the diabetic control group had constant hyperglycaemia all through the experiment. In other words, it has been shown in this study that the albino rats that were confirmed diabetic and not treated with tomato had hyperglycaemia that lasted throughout the experiment while on the other hand, diabetic animals treated with tomato showed reduced fasting blood glucose levels on the 7th and 14th day (the last day of the experimental duration)as showed in Table 1. Although there was significant differerence $(p<0.05)$ between the normal control and treatment groups, oral administration of tomatoes extract highly reduced the fasting blood glucose level in diabetic rats at 7 th and 14th days compared to diabetic control group (Group II). This revelation maybe as a result of the phytochemical constituents as well as caroteboids and chromium. Carotenoids and chromiun have been shown to have affect glucose metabolism and insulin secretion [15-18]. Similarly, it has been reported that intake of carotenoid rich fruit protects against hyperglycemic induced damage in diabetes mellitus $[17,19,20]$.

In this study, oral administration of tomato even at $50 \mathrm{mg} / \mathrm{kg}$ can potentiate effect of lowering fasting blood sugar though this study could not elucidate the mechanism by which tomatoes lowers blood glucose levels, it may be probably due to their phytochemical constituents, especially carotenoids and chromium [15]. It was also reported that tomatoes are rich in fibre [21]. Fibre in tomato lowers gastric emptying and therefore absorption of sugar into the bloodstream, positively impacting diabetes.

This study as seen from Table 2, the results show a significant increase in total cholesterol, triglyceride, LDLCholesterol, and significant decrease in HDL-Cholesterol levels in untreated diabetic rats, this proved the results of other investigator that said untreated diabetes is associated with impairment in lipid metabolism [22]. It was also reported that hypercholesterolemia in induced-diabetic rats results from increased intestinal absorption and synthesis of cholesterol [23] has been demonstrated in this study where the diabetic untreated rats had high serum cholesterol.

However, animals receiving oral administration of tomatoes have significantly lower level of serum cholesterol. Tomatoes are rich in fibre and fibre helps in transforming the nature of what is contained in the gastrointestinal tract and this affect how other nutrients and chemicals are absorbed [24]. Soluble fibre binds to bile acids in the small intestine and lowers its absorption This in turns lowers cholesterol levels in the blood [25]. However, the fall in serum total cholesterol was less than that of the normal control group and the fall was proportionate to the increase in the dose of tomatoes extract, with the highest reduction observed in the highest dose $(200 \mathrm{mg} / \mathrm{kg})$.

The diabetic group has the lowest HDL-cholesterol levels compaired with all the treatment groups. Some constituents of tomatoes like lycopene and vitamin $\mathrm{E}$ are powerful antioxidant. The constituent's vitamin $\mathrm{E}$ and lycopene in tomato are known to prevent LDL oxidation effectively [26].There was also significant increase in serum triglyceride levels in the diabetic control compared with the treatment groups, this is in accordance with fact that untreated diabetes is associated with increased in serum triglyceride levels [27]. However, in the treatment groups 
there was significant decrease in the serum levels of triglycerides, although levels are higher than that of the normal control group.

The diabetic control had the highest level of LDLCholesterol, while the other treated groups and the normal control groups showed a decreased levels of serum LDLcholesterol, but the levels in all the treatment groups were significantly $(\mathrm{p}<0.05)$ different from the normal control. Research shows that lycopene lowers the oxidation of LDLcholesterol [28]. This study shows that in the diabetic control there was a significant increase in the serum total protein compared with both the normal control and the treatment groups. A previous study has shown that one of the complications of untreated diabetes is the increase in total serum protein [29].

\section{CONCLUSION}

Tomatoes reduced fasting blood sugar, LDL-cholesterol,total cholesterol and triglycerides levels in alloxan induced diabetic rats.It also increased the levels of HDL-cholesterol.Tomatoes may have hypoglycaemic effects and may also reduce the risk of cardiovascular diseases by decreasing the levels of serum triglyceride,total cholesterol and LDL cholesterol. Further studies should be carried out on its toxicity and the actual component of tomato that have the hypoglycaemic property.

\section{REFERENCE}

1. International Diabetes Federation. Diabetes Facts \& Figures. IDF diabetes atlas; $9^{\text {th }}$ Edition. 2019

2. Owu, D.U., Antai, A.B., Udofia, K.H., Obembe, A.O., Obasi, K.O.and Eteng, M.U. Vitamin C improves basal metabolic rate and lipid profile in alloxan-induced diabetes mellitus in rats, J. Biosciences. 2006; 31(5), 575-579.

3. Nayeeminnisa, A. Alloxan diabetes-induced oxidative stress and impairment of oxidative defense system in rat brain: neuroprotective effects of cichoriumintybus, Int $\mathrm{J}$ Diabetes \& Metabolism. 2009; 17, 105-109.

4. Edem,D.O.Hypoglycemic effects of ethanolic extracts of Alligator Pear Seed (Persea americana Mill) in rats, European Journal of ScientificResearch. 2009; 33(4), 669-678.

5. Prince, S.M and Menon, VP. Hypoglycemic and other related actions of Tinospora cardifolia roots in alloxan induced diabetic rats, J. Ethnopharmacol. 2000; 70, 9-15.

6. Jelodar, G., Mohsen, M.and Shahram, S. Effect of walnut leaf, coriander and pomegranate on blood glucose and histopathology of pancreas of alloxan - induced diabetic rats, African Journal of Traditional, Complementary and Alternative Medicines. 2003; 3, $299-305$.

7. Rajagopal,K. and Sasikala,K. Antihyperglycaemic and antihyperlidaemic effects of Nymphaea stellata in alloxan-induced diabetic rats,Singapore Med J. 2008; (49) 137-141

8. DerMarderosian, A. The Review of Natural Products. Facts and Comparisons. St.Louis. 2001; p. 379.

9. DiMascio, P., Kaiser ,S.and Sreies, H. Lycopene as the most efficient biological carotenoid singlet oxygen quencher. Arch Biochem Biophys. 1989; 274 : 532-8.

10. Ziegler, R.G.and Vogt, T.M. Tomatoes, lycopene and risk of prostate cancers Pharm Biology. 2002; 40: 59-69.

11. Stanley, M.P. and Venogopal, M.P. Antioxidant action of Tinospora, Cordiofolia root extract in alloxan-induced diabetic rats. Phytother. Res. 2001; 15: 213-218.

12. Trinder, P. Determination of glucose in blood using glucose oxidase with an alternative oxygen acceptor, Ann. Clin. Biochem. 1969; 6, 24-25.

13. Friedwald, W. T., Levy, R. I. and Fredrickson, D. S. Estimation of the concentration of low density lipoprotein cholesterol plasma without use of the preparative ultracentrifuge. Clinical Chemistry. $1972 ; 18,499-502$

14. Gornall, A.G., Bardawill, C.S. and David ,M.M. Determination of serum proteins by means of Biuret reaction. J.Biol. Chem. 1949; 177: 751 .
15. Anderson, R.A. Chromium in the prevention and control of diabetes. Diabetes Metab. 2000; 26: 22-27.

16. Head, K. and Chowka P. Controlling blood sugar with nutrients and botanicals. Adv. Nurse. Pract. 2003; 11: 22-22.

17. Ylonen, K., Alfthan G., Groop L., Saloranta, C.and Aro, A. Dietary intakes and plasma concentrations of carotenoids and tocopherols in relation to glucose metabolism in subjects at high risk of type 2 diabetes: The Botnia dietary study.Am. J. Clin. Nutr. 2003; 77 1434-1441.

18. Jain, S.K., Rain J.L. and Croad J.L. Effect of chromium niacinate and chromium picolinate supplementation on lipid peroxidation, TNF- $\alpha$, IL- 6, CRP, glycated hemoglobin, triglycerides and cholesterol levels in blood of streptozotocin treated diabetic rats. Free Radic. Biol. Med. 2007; 43: 1124-1131.

19. Suzuki, K., Ito Y., Nakamura, S., Ochial, J. and Aoki, K. Relationship between serum carotenoids and hyperglycaemia; A population based cross-sectional study. J. Epidemiol. 2002; 12 : 357-366.

20. Ali, M.M. and Agha, F.G. Amelioration of streptozotocin-induced diabetes mellitus, oxidative stress and dyslipidemia in rats by Lycopersicon esculentum extract lycopene. Scandinavian J. Clin. Lab. Invest. 2009; 69:371-379.

21. Heber, D. and Lu, Q.Y.,(2002). Overview of mechanisms of action of lycopene. Exp Biol. 2002; 227(10):920-3.

22. Mendez, J.D. and Balderas, F.Regulation of hyperglycemia and dyslipidemia by exogenous L-arginine in diabetic rats. Biochimie. 2001; 83(5):453-8

23. Mathe, D. Dyslipidemia and diabetes animal models. Diabetes Metab. 1995; 21(2): 106

24. Eastwood,M. and Kritchevsky,D. Dietry fibres: how did we get where we are? Annu Rev Nutr 2005; 25: 1-8.

25. Anderson, J.W., Baird,P. and Davis, R.H. Health benefits of dietary lycopene .Nutr Rev. 2009; 64(2):188-205.

26. Junji, T. Tomatoes and Its Medicinal Properties. Retrieved from http://www.pyroenergen.com/newsletter.html. 2010.

27. Malik, S.and Kashyap, M. L. Niacin, lipids, and heart disease. Curr Cardiol Rep. 2003; 5(6):470-6.

28. Fuhrman, B., Volkova,N., Rosenblat,M.,and Aviram M. Lycopene synergistically inhibits LDL oxidation in combination with vitamin $\mathrm{E}$, glabridin, rosmarinic acid, carnosic acid, or garlic. Antioxid Redox Signal. 2000; 2(3):491-506.

29. Gul, A. and Rahman, M. A. Comparison of blood protein levels between diabetic and non-diabetic patients with retinopathy. J Coll Physicians Surg Pak. 2006; 16(6):408-11. 